\title{
Processing, Microstructure and Mechanical Properties of the CrMnFeCoNi High-Entropy Alloy
}

\author{
BERND GLUDOVATZ ${ }^{1,},{ }^{1,4}$ EASO P. GEORGE, ${ }^{2}$ \\ and ROBERT O. RITCHIE ${ }^{1,3}$ \\ 1.-Materials Sciences Division, Lawrence Berkeley National Laboratory, Berkeley, CA 94720, \\ USA. 2.-Institute for Materials, Ruhr University, 44801 Bochum, Germany. 3.-Department of \\ Materials Science \& Engineering, University of California, Berkeley, CA 94720, USA. \\ 4.--e-mail: bpgludovatz@lbl.gov
}

Equiatomic multi-component alloys, referred to variously as high-entropy alloys, multi-component alloys, or compositionally complex alloys in the literature, have recently received significant attention in the materials science community. Some of these alloys can display a good combination of mechanical properties. Here, we review recent work on the processing, microstructure and mechanical properties of one of the first and most studied high-entropy alloys, namely the single-phase, face-centered cubic alloy $\mathrm{CrMnFeCoNi}$, with emphasis on its excellent damage tolerance (strength with toughness) in the temperature range from room temperature down to liquid nitrogen temperature.

\section{INTRODUCTION}

The mechanical properties required for metallic materials in most structural applications rarely can be achieved in pure metals and are generally attained through the addition of alloying elements. Traditionally, metallic alloys have consisted of a dominant element, such as iron in steels, to which small amounts of alloying elements are added, for example, carbon for strength. High-entropy alloys (HEAs) represent a radical departure from these notions ${ }^{1-3}$ since they are multi-principal-element metallic systems that contain high concentrations of different elements in near equiatomic proportions. Indeed, in many respects, these alloys represent a new field of metallurgy that focuses attention away from the corners of alloy phase diagrams towards their centers, ${ }^{1}$ thereby enabling numerous new materials.

One of the most notable HEAs to date, $\mathrm{CrMnFe}$ $\mathrm{CoNi}$, is a case in point. Although first identified a decade ago by Cantor et al., ${ }^{1}$ the alloy had not been thoroughly investigated until recently, yet is clearly scientifically interesting from several perspectives. Firstly, it is not obvious why an equiatomic fiveelement alloy, in which two of the elements $(\mathrm{Cr}, \mathrm{Fe})$ have a body-centered cubic (bcc) structure, one (Ni) is face-centered cubic (fcc), one (Co) is hexagonal closed-packed (hcp), and one (Mn) has a complex A12 structure, should form a single-phase fcc structure. ${ }^{4}$ Notwithstanding the theory underlying the notion of high configurational entropy being able to stabilize solid solutions, ${ }^{2}$ it has been shown that multiple-element equiatomic materials are not guaranteed to be single-phase simply through increasing the number of alloying elements. Cantor et al., for example, produced an alloy containing 20 elements that nevertheless crystallized into an extremely brittle microstructure comprising multiple phases. ${ }^{1}$ Secondly, some of this alloy's properties are quite unlike those of pure fcc metals with a strongly temperature-dependent yield strength but only a small strain-rate dependence. ${ }^{5,6}$ However, the alloy also displays an excellent combination of strength, ductility and fracture toughness particularly at lower temperatures ${ }^{6,7}$ which together with its ease of processing, described in the following section, makes it a promising material on the basis of which new advanced structural alloys may be developed..$^{8-10}$

In this review, we focus solely on the model fcc alloy $\mathrm{CrMnFeCoNi}$ and pay attention to its processing, mechanical properties and structural performance, particularly at cryogenic temperatures. 


\section{PROCESSING AND MECHANICAL PROPERTIES OF CrMnFeCoNi}

\section{Material Processing and Microstructure}

In their 2004 paper, Cantor et al. ${ }^{1}$ first introduced the fcc high-entropy alloy $\mathrm{CrMnFeCoNi}$. An optical micrograph of its cast microstructure was included in that paper. The alloy had been induction melted in an alumina crucible and exhibited significant dendritic segregation despite being quite small and weighing only about $10 \mathrm{~g}$. A comparable size button of this alloy that was subsequently arc-melted in 2008 at the Oak Ridge National Laboratory (ORNL) on a water-cooled copper hearth exhibited less severe segregation (Fig. 1), probably because of its higher cooling rate. Subsequently, many larger ingots weighing approximately $500 \mathrm{~g}(\sim 25 \mathrm{~mm}$ in diameter and $127 \mathrm{~mm}$ long) were produced at ORNL by arc melting and drop casting. These ingots also exhibited dendritic microstructures but it was possible to homogenize them by annealing at 1000$1200^{\circ} \mathrm{C}$ for $24-48 \mathrm{~h} .^{4}$ In general, the ease of homogenization depends on the dendrite spacing in castings, which varies inversely with the cooling rate during solidification; consistent with this notion, it was reported recently that homogenization was easier in twin-roll cast alloys than in suction cast alloys because of the finer dendrites in the former. ${ }^{11}$ Recently, even larger ingots $(40 \mathrm{~mm}$ in diameter) have been successfully homogenized at the Ruhr University in Bochum by annealing at $1200^{\circ} \mathrm{C}$ for $48 \mathrm{~h}^{12}$ Whether this trend will continue as casting sizes increase to industrial scales remains an open question, given recent indications that inter-diffusion rates in this five-element alloy are slower than those in less complex alloys, as well as the self-diffusion rates of the pure constituent elements. ${ }^{13}$

In the laboratory-scale castings that have been investigated to date, the grains after homogenization (Fig. 2a) and after subsequent deformation and short-term annealing (Fig. 2b) can be quite large, of the order of a few hundred micrometers, ${ }^{5,12,14}$ and

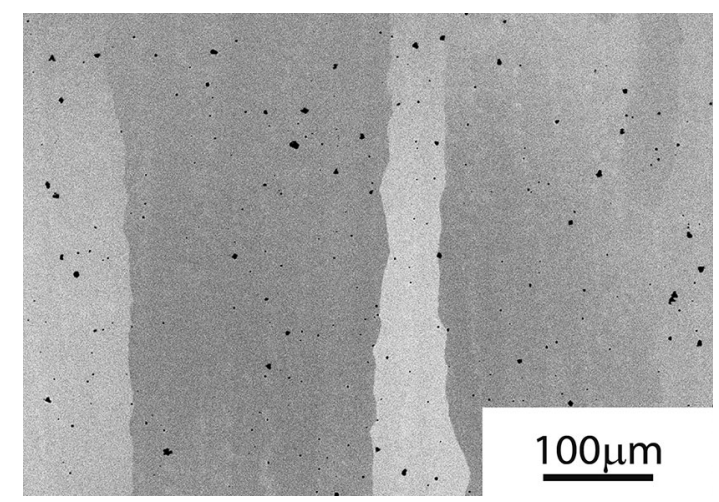

Fig. 1. Back-scattered electron micrograph of the as-cast high-entropy alloy CrMnFeCoNi. A button of $\sim 10 \mathrm{~g}$ weight, arc-melted on a water-cooled copper hearth, shows compositional variations due to dendritic solidification and scattered oxides as dark particles. they tend to be relatively equiaxed. ${ }^{5,14}$ The composition is uniform and close to equiatomic, both through the cross-section of the ingot and over its length. ${ }^{12}$ Based on microstructural analyses using x-ray diffraction (XRD), scanning electron microscopy (SEM), and atom probe tomography (APT), after homogenization at relatively high temperatures $\left(>1000^{\circ} \mathrm{C}\right)$, the HEA was shown to be a singlephase solid solution with the fcc structure at the respective length scales of these analysis techniques. $^{5,11}$ Small inclusions (Fig. 2a), which are difficult to avoid in normal melting practice when the alloys contain reactive elements, are present in most of the castings evaluated (and they remain even after thermomechanical processing). They appear to be Mn-containing oxides based on the results of chemical analyses by energy dispersive spectroscopy ${ }^{5,12}$ and the fact that they are largely absent in the Mn-free quaternary alloy $\mathrm{FeCoNiCr}{ }^{5}$ Transmission electron microscopy (TEM) studies with selected area diffraction have yet to be conducted to fully characterize their structure and improve our understanding of their origin. So far, detailed mechanical characterizations have not been carried out on the $\mathrm{CrMnFeCoNi}$ alloy in the cast and/or homogenized condition, which is a shortcoming that will have to be rectified if alloys based on this composition are to be used as castings in the future.

Meanwhile, because of its excellent malleability, most mechanical testing to date has been performed on wrought material. To produce wrought material, the $\mathrm{CrMnFeCoNi}$ alloy can be deformation-processed in a variety of ways including rolling at elevated temperature,${ }^{5}$ room temperature ${ }^{6}$ cryogenic temperature,$^{14}$ swaging at room temperature ${ }^{15}$ and severe plastic deformation (SPD) by high-pressure torsion (HPT) at room temperature. ${ }^{15}$ During multipass rolling at $1000^{\circ} \mathrm{C}$ to a total reduction in thickness of $\sim 90 \%$, the alloy undergoes dynamic recrystallization resulting in an equiaxed microstructure with $\sim 30 \mu \mathrm{m}$ grains containing numerous twins indicative of a low stacking fault energy for this alloy. ${ }^{5,16}$

Extensive deformation by multi-pass rolling at room temperature is possible, with total reductions in thickness of as much as $90 \%$ without the need for any intermediate anneals. ${ }^{6}$ High degrees of deformation are also possible by multi-step swaging at room temperature without intermediate annealing, ${ }^{15}$ resulting in a reduction of diameter from $40 \mathrm{~mm}$ to $16.5 \mathrm{~mm}$ (i.e., area reduction of $\sim 80 \%$ ). While it is generally difficult to perform electron back-scattered diffraction (EBSD) analyses on specimens containing a high density of defects after heavy deformation, it has nevertheless been possible to obtain clear Kikuchi patterns from a few isolated regions of swaged rods. From analyses of such patterns, it was concluded ${ }^{12}$ that the swaged rods exhibit a strong $\langle 111\rangle$ texture parallel to the rod axis, along with a minor $\langle 001\rangle$ fiber texture. There is 

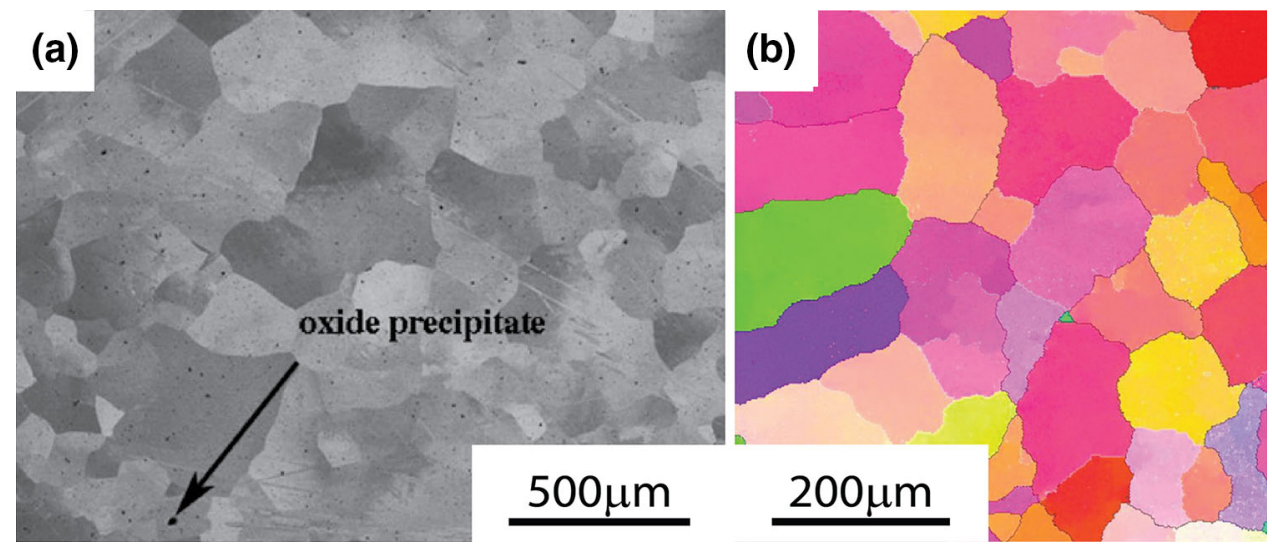

Fig. 2. Grain size and structure of the homogenized CrMnFeCoNi alloy. (a) After homogenization the grains were equiaxed and a few hundred micrometers in size with small oxide inclusions. (b) Subsequent slight deformation and short-term annealing after homogenization but prior to fullscale deformation processing results in grain sizes still of the order of a few hundred micrometers. (Reprinted from Refs. 5,14 with permission from Elsevier.).

no texture along directions normal to the long axis of the swaged rods because of its axial symmetry. ${ }^{12}$ After annealing at a relatively low temperature ( $870 \mathrm{~K}$ for $1 \mathrm{~h}$ ), the microstructure appears identical to the as-swaged microstructure with no evidence of any recrystallization. However, recovery processes clarified most of the Kikuchi patterns and, after they were indexed, it was concluded that the texture was the same as that of the as-swaged rod. ${ }^{12}$

Cryogenic rolling at $77 \mathrm{~K}$ has also been performed with the rolls and sheet immersed in liquid nitrogen to allow for isothermal conditions. ${ }^{14}$ Total reductions in thickness of up to $80 \%$ were possible without intermediate anneals. The microstructural evolution at $77 \mathrm{~K}$ was similar to that during room temperature rolling, except that twinning set in earlier and the fraction of twinned grains reached its saturation value at lower strains at $77 \mathrm{~K}$ than at room temperature. ${ }^{14}$ Dislocation density showed the opposite trend, indicating the different relative contributions of deformation twinning and dislocation plasticity to the overall deformation process at the two different temperatures. These trends are somewhat similar to the behavior noted earlier in tensile-tested specimens, ${ }^{6}$ except that twinning was not observed at room temperature in that study, only in specimens tested at $77 \mathrm{~K}$. The different stress states during rolling and tensile testing might possibly account for this difference, along with the larger grain size of the starting material used for rolling. Extensive nanotwinning was also observed after HPT was performed at room temperature on the cast and homogenized HEA having a large grain size. ${ }^{17}$ In addition to any effect of grain size, another possible reason for the onset of nanotwinning at room temperature might be the high internal stresses generated during SPD. Clearly, further studies are needed to improve our understanding.

After rolling at room temperature recrystallization by annealing at elevated temperatures $\left(>800^{\circ} \mathrm{C}\right)$ results in almost perfectly equiaxed single-phase grains ${ }^{6}$ containing numerous annealing twins (Fig. $3 a)^{5,6}$ and very low dislocation densities as shown in the TEM micrograph in Fig. $3 b^{6}$ The grain sizes depend on the degree of cold work as well as the annealing temperature/time ${ }^{18}$ and the results can be summarized as follows. For reductions in thickness (cold work) greater than approximately 85\%, full recrystallization occurred after annealing for $1 \mathrm{~h}$ at $800^{\circ} \mathrm{C}$. For lower thickness reductions, higher annealing temperatures were needed $\left(900^{\circ} \mathrm{C}\right.$ for thickness reductions of $\sim 40$ to $60 \%$, and $1000{ }^{\circ} \mathrm{C}$ for $20 \%)$. The as-recrystallized grain size $(\sim 5 \mu \mathrm{m}$ at $800{ }^{\circ} \mathrm{C} / 1 \mathrm{~h}$ ) was remarkably constant and independent of cold work (in the range $~ 60-95 \%$ ). However, for higher annealing temperatures and lower amounts of cold work, there was more scatter in the grain size. An analysis of the isochronal and isothermal grain growth kinetics in two independent studies ${ }^{18,19}$ found the grain growth exponent and the activation energy to be 3 and $322 \mathrm{~kJ} / \mathrm{mol}$, respectively. This relatively high activation energy was attributed ${ }^{19}$ to sluggish diffusion in this $\mathrm{HEA}^{13}$ in addition to which the activation energy for grain growth was found to be comparable to that of the slowest diffusing species $(\mathrm{Ni})$ in $\mathrm{CrMnFeCoNi} .{ }^{13}$ Roughly similar recrystallization and grain growth kinetics were recently obtained ${ }^{12}$ for rods swaged at room temperature and then annealed at $870-1270 \mathrm{~K}$. After full recrystallization and subsequent grain growth, the grain orientations became close to random with only a weak texture reminiscent of the deformation texture. ${ }^{12}$ Additionally, grain size distributions were found to be homogeneous at various points on the rod cross-sections and lengths, indicating that they can be considered as isotropic polycrystals (which is relevant in the determination of certain polycrystalline mechanical properties such as elastic constants).

After severe plastic deformation by HPT (strains of approximately $5000 \%$ ), grain size was significantly reduced, down into the nanoscale $(\sim 50 \mathrm{~nm})$, but the cast and homogenized HEA retained its true solid 

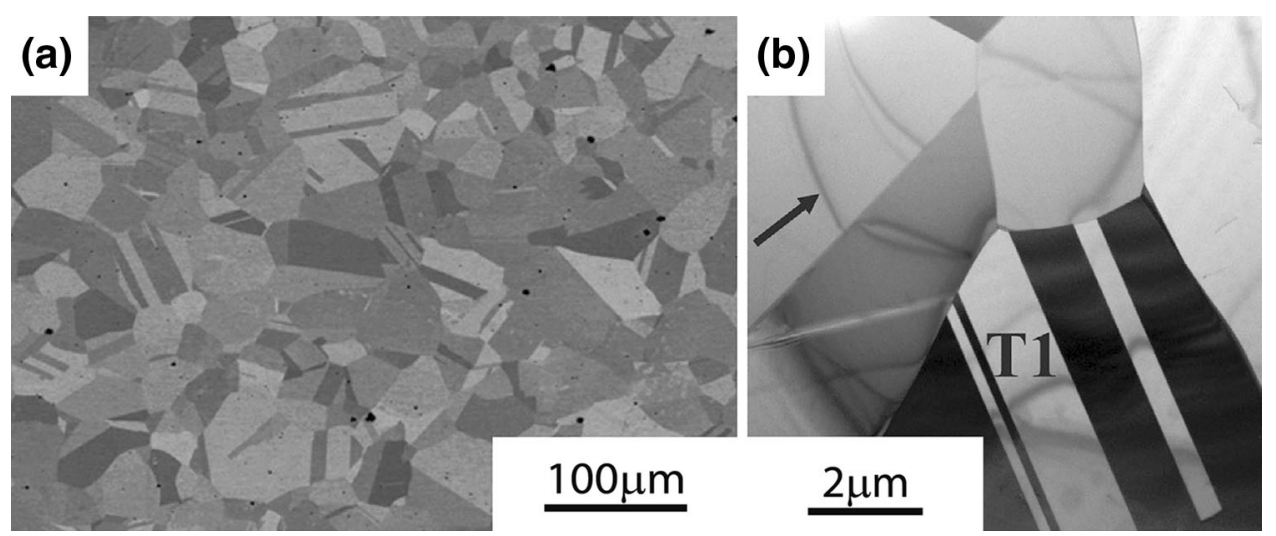

Fig. 3. Microstructure of the rolled and recrystallized CrMnFeCoNi material. (a) The alloy exhibits almost perfectly equiaxed grains with numerous annealing twins and (b) very low dislocation densities after recrystallizing. Examples of annealing twins and bend contours are marked by $\mathrm{T} 1$ and the arrow, respectively. (Reprinted from Ref. 5, with permission from Elsevier and from Ref. 6, with permission from Elsevier.).
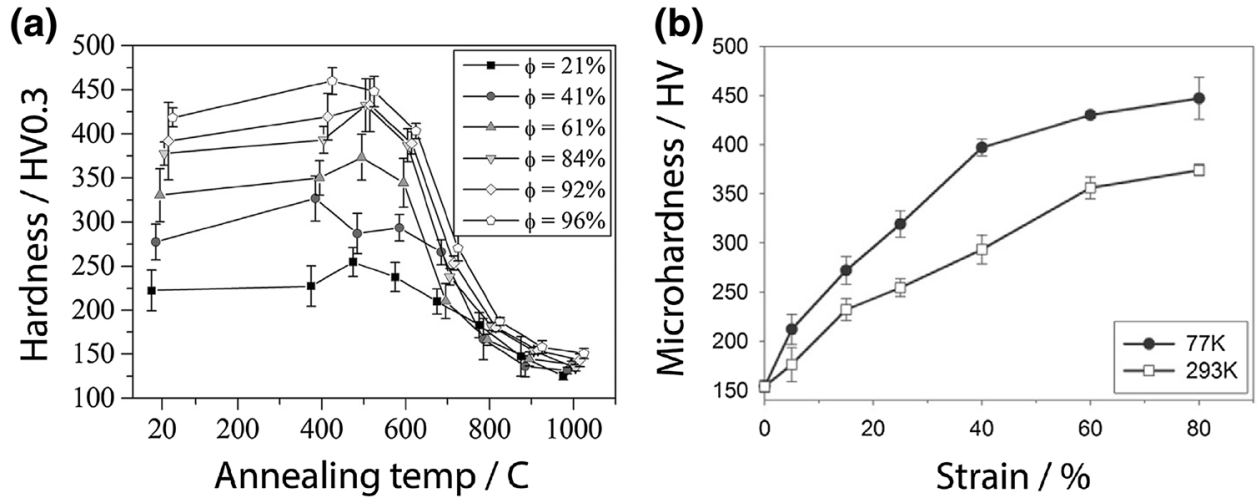

Fig. 4. Hardness of the CrMnFeCoNi alloy as a function of strain during room temperature and cryogenic rolling. (a) At room temperature, the material's hardness increases monotonically with increasing cold work (degree of deformation). Subsequent annealing results in a slight increase in hardness followed by a rapid decrease. (b) Cryo-rolling at $77 \mathrm{~K}$ leads to a similar but noticeably higher hardness increase with strain for the whole deformation interval. (Reprinted from Ref. 14, with permission from Elsevier and from Ref. 18, with permission from Elsevier.).

solution state down to the atomic scale as shown recently by TEM and APT. ${ }^{17}$ However, subsequent annealing at $450^{\circ} \mathrm{C}$ resulted in nanoscale precipitation in the HEA matrix: first to appear were NiMn and $\mathrm{Cr}$, followed at longer times by FeCo. ${ }^{17}$ These results are partially consistent with recent phase diagram calculations, ${ }^{20}$ in which it was predicted that the CrMnFeCoNi HEA would be stable as a single phase fcc solid solution at temperatures above $600^{\circ} \mathrm{C}$ but would decompose into a fcc and a bcc phase at lower temperatures. Further refinement of the phase diagram calculations is needed, however, since the second phases persisted at annealing temperatures as high as $750^{\circ} \mathrm{C}$, and disappeared completely only at $800^{\circ} \mathrm{C},{ }^{17}$ contrary to the prediction of a single-phase solid solution above $600^{\circ} \mathrm{C} .^{20}$

\section{Mechanical Properties}

\section{Hardness}

The hardness of the CrMnFeCoNi alloy increases significantly as a function of the imposed compressive strain during rolling (Fig. 4) at both room temperature (Fig. $4 \mathrm{a})^{14,18}$ and $77 \mathrm{~K},{ }^{14}$ albeit more after cryo-rolling (Fig. 4b). This response is consistent with the high strain-hardening rate of this alloy, especially as the temperature is lowered into the cryogenic range. ${ }^{5,6}$ After cold work, the hardness evolution as a function of annealing has been studied in both rolled sheets ${ }^{18}$ and swaged rods. ${ }^{12}$ In both cases, there is an initial hardness increase at low annealing temperatures contrary to the softening expected from recovery and recrystallization processes. Starting from various rolled states (2196\% reduction in thickness), there is a slight but distinct increase in hardness after $1 \mathrm{~h}$ anneals at temperatures of $\sim 400-500{ }^{\circ} \mathrm{C}$ (Fig. 4a). Similarly, starting from the swaged state $(80 \%$ reduction in area), there is again a slight increase in hardness after $1 \mathrm{~h}$ at $600^{\circ} \mathrm{C}$. EBSD and back-scattered electron (BSE) scanning electron microscopy (SEM) images showed that recrystallization had not yet started during these low-temperature exposures. Analogous, but more dramatic hardness increases were reported recently in this HEA after HPT followed by annealing, especially at $4500^{\circ} \mathrm{C} ;{ }^{17}$ its cause was attributed to the nanoscale phase decomposition described in the previous section. Beyond the 
peak in hardness (which occurs between $\sim 400^{\circ} \mathrm{C}$ and $600^{\circ} \mathrm{C}$ ), hardness decreases precipitously as a result of recrystallization, and then more gradually as grain growth occurs. ${ }^{12,18}$ Hardness of the HPT alloy also peaks at around $450^{\circ} \mathrm{C}$ but, in addition to grain growth, another contributory factor to its softening is a decrease in the amount of second phases with increasing temperature and their complete disappearance at around $800^{\circ} \mathrm{C} .{ }^{17}$

The decrease in hardness with increasing grain size follows a classical Hall-Petch relationship for grain sizes in the range of $\sim 4-26 \mu \mathrm{m} .{ }^{19}$ The slope of the Hall-Petch curve was found to be higher than the upper bound for fcc metals, suggesting that slip transfer across grain boundaries in the CrMnFe CoNi alloy faces significant resistance. This conclusion, as well as the high friction stress implied in the above study, need to be examined more thoroughly by investigating Hall-Petch behavior in uniaxial tests (tension or compression).

\section{Elastic Constants}

Temperature dependencies of the polycrystalline elastic moduli of the $\mathrm{CrMnFeCoNi}$ alloy have been measured in the cryogenic range from room temperature down to $55 \mathrm{~K}$ (Fig. 5a), ${ }^{21}$ as well at higher temperatures from 200 to $1000 \mathrm{~K}$ (Fig. 5b) ${ }^{15}$ The two independent studies both used the ultrasonic resonant frequency technique but significantly different sample geometries. Nevertheless, over the temperature range of overlap ( $200 \mathrm{~K}$ to room temperature), there was excellent agreement in the measured shear and Young's moduli ( $G$ and $E$, respectively) (Fig. 5c), providing a measure of confidence in the reported values. At room temperature, the values of $G$ and $E$ are 80 and $202 \mathrm{GPa}$, respectively, while at $77 \mathrm{~K}$ the corresponding values are 85 and $214 \mathrm{GPa}$, respectively. Over the entire temperature range covered by the two studies,
$55-1000 \mathrm{~K}$, a regression analysis of the data yielded the following expressions for the temperature dependencies of the elastic moduli (in GPa): ${ }^{15}$

$$
\begin{gathered}
G=85-16 /\left(e^{448 / T}-1\right) \\
E=214-35 /\left(e^{416 / T}-1\right),
\end{gathered}
$$

where $T$ is the absolute temperature in Kelvin. An important conclusion from these studies is that the temperature dependence of the shear modulus of $\mathrm{CrMnFeCoNi}$ is, if anything, even weaker than that of pure fcc nickel. This is relevant because, as discussed below, the $\mathrm{CrMnFeCoNi}$ alloy exhibits a strong temperature dependence of strength, especially at cryogenic temperatures, ${ }^{5,6}$ unlike the behavior of pure fcc metals such as Ni that show very weak temperature dependence between room temperature and $77 \mathrm{~K}^{22}$ While the reason for this anomalous strengthening in the $\mathrm{CrMnFeCoNi}$ alloy remains unclear, what can be ruled out is that it is caused by an anomalously strong temperature dependence of $G .^{21}$

Room-temperature single crystal elastic constants of the $\mathrm{CrMnFeCoNi}$ alloy have been determined by applying stress to a polycrystalline sample and using in situ neutron diffraction to measure the elastic strains across different crystal planes. ${ }^{23}$ The alloy shows relatively strong elastic anisotropy with values of 172,108 , and $92 \mathrm{GPa}$ for $\mathrm{C} 11, \mathrm{C} 12$, and $\mathrm{C} 44$, respectively, which yields a value for the shear anisotropy, $A$, of $\sim 2.8(A=2 \mathrm{C} 44 /(\mathrm{C} 11-\mathrm{C} 12)$.

\section{Tensile Properties}

Gali and George ${ }^{5}$ were the first to measure uniaxial tensile properties of the $\mathrm{CrMnFeCoNi}$ alloy in the recrystallized state and reported that it exhibits a strong temperature dependence of yield, $\sigma_{\mathrm{y}}$, and
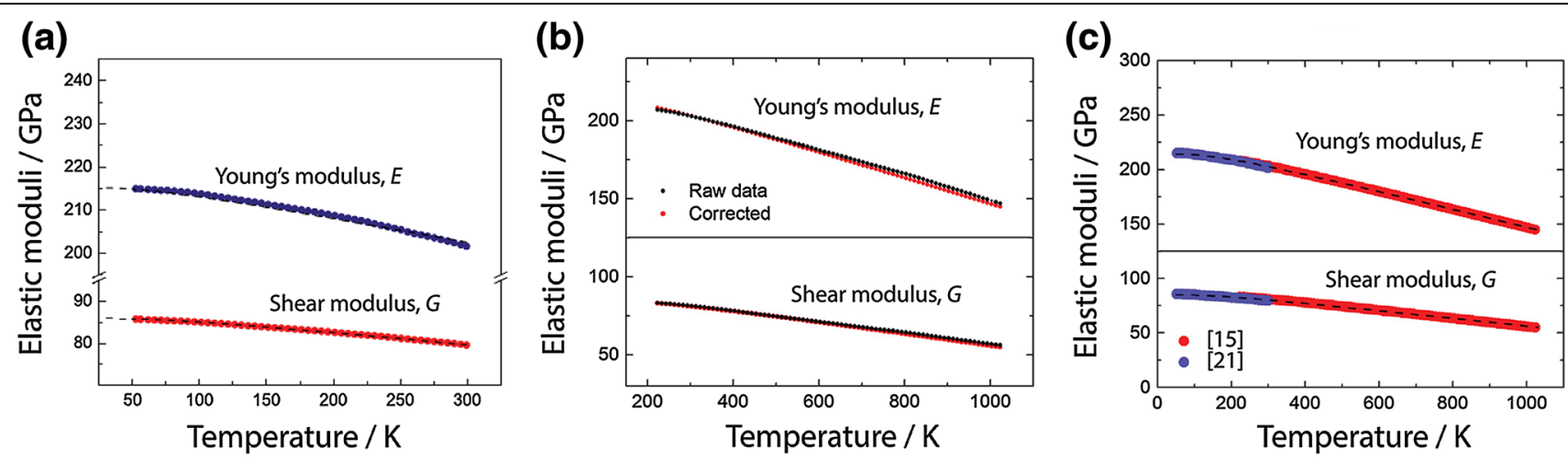

Fig. 5. Temperature dependence of the shear modulus, $G$ and Young's modulus, E, of CrMnFeCoNi in the range 55-1000 K. (a) Resonant ultrasound measurements of the elastic moduli of the $\mathrm{CrMnFeCoNi}$ alloy show both a monotonically decreasing $G$ and $E$ in the cryogenic range from room temperature down to 55 and (b) at higher temperatures between $200 \mathrm{~K}$ and $1000 \mathrm{~K}$. (c) In the overlap region (200 $\mathrm{K}$ to room temperature), the two studies show excellent agreement in the data so that at room temperature, the values of $G$ and $E$ are 80 and $202 \mathrm{GPa}$, respectively, whereas at $77 \mathrm{~K}$ the corresponding values are 85 and $214 \mathrm{GPa}$, respectively. (Reprinted from Ref. 15, with permission from Elsevier and from Ref. 21, with permission from Elsevier.). 
ultimate tensile strength, $\sigma_{\mathrm{UTS}}$. Their results were subsequently validated by Otto et al. ${ }^{6}$ over a wider range of grain sizes in the range 4-160 $\mu \mathrm{m}$. Figure 6a shows representative tensile data from these two studies. Such behavior is characteristic of bcc metals and certain fcc solid-solution alloys but is not typically observed in pure fcc metals. Interestingly, the alloy shows little to no effect of strain rate on tensile properties (Fig. 6 b) ${ }^{5}$ and the marked temperature-dependent increase in strength is accompanied by a substantial increase in strain to failure, $\varepsilon_{\mathrm{f}}$ (ductility) with decreasing temperature (Fig. 6a); ${ }^{6}$ this runs counter to most other materials where an inverse dependence of ductility and strength is invariably seen. ${ }^{24}$ The values of $\sigma_{\mathrm{y}}, \sigma_{\mathrm{UTS}}$, and $\varepsilon_{\mathrm{f}}$ for the investigated grain sizes at room temperature are in the ranges of $200-350 \mathrm{MPa}, 550-650 \mathrm{MPa}$, and $0.6-0.8$, respectively, while at $77 \mathrm{~K}$ the corresponding values are $450-600 \mathrm{MPa}, 900-1100 \mathrm{MPa}$, and $0.9-1.1$, respectively.

Many of these properties may be the result of the alloy's capacity to sustain a high work hardening rate $^{5,6}$ with strain-hardening exponents of $n \sim 0.4$ over a wide range of strains. ${ }^{7}$ TEM studies ${ }^{6}$ show that, at room temperature, deformation occurs by the planar glide of $1 / 2\langle 110\rangle$ dislocations on $\{111\}$ planes leading eventually to the formation of pronounced cell structures at high strains. ${ }^{6}$ With the temperature decreasing towards $77 \mathrm{~K}$, the contribution of nanoscale twinning at high strains progressively increases. These deformation mechanisms, particularly the deformation twinning, serve to provide a steady source of effective strain hardening which acts to delay the onset of necking instability. Consequently, with decreasing temperatures, the alloy displays a marked increase in strain to failure (ductility) (Fig. 6a) coupled with an increase in strength, characteristics which generate exceptional damage-tolerance in the alloy at cryogenic temperatures ${ }^{5,6}$

After severe plastic deformation by HPT, the CrMnFeCoNi HEA exhibits an exceptionally high yield strength approaching $2 \mathrm{GPa}^{17}$ This is likely the result of grain refinement down to the nanoscale, although local distortions and internal stress generated during SPD may also play a role. Limited elongation was apparent in the stress-displacement curves even at such a high stress level
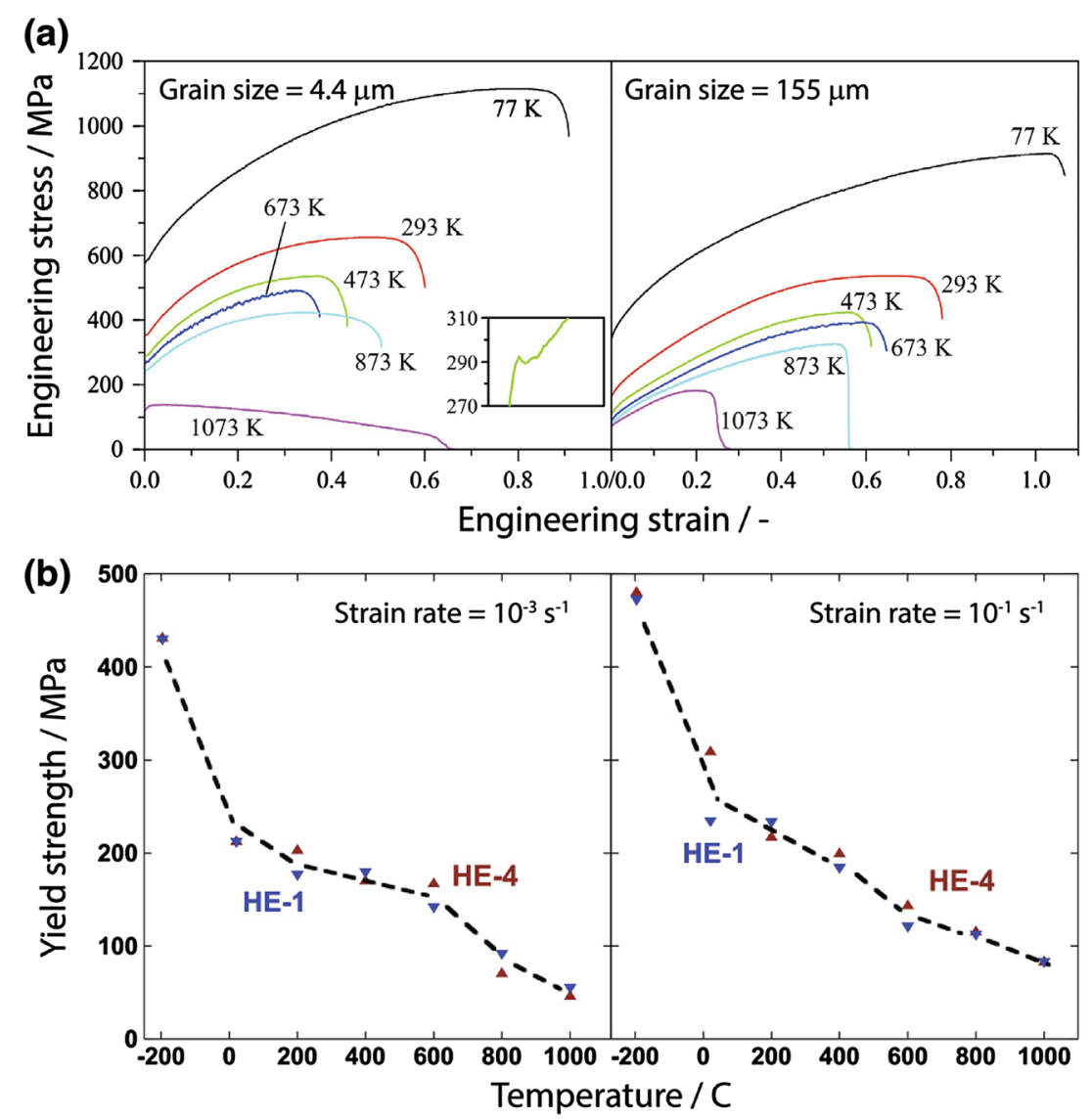

Fig. 6. Tensile properties of the CrMnFeCoNi alloy. (a) Engineering stress-strain curves from uniaxial tensile tests on recrystallized samples with grain sizes between $4 \mu \mathrm{m}$ and $160 \mu \mathrm{m}$ show an increasing yield, $\sigma_{\mathrm{y}}$, and ultimate tensile strength, $\sigma_{\mathrm{UTS}}$, and a trend to higher strains to failure, $\varepsilon_{\mathrm{f}}$ (ductility) with decreasing temperature in the range $77-1000 \mathrm{~K}$. (b) The CrMnFeCoNi alloy (HE-1) shows only a very limited effect of the $0.2 \%$ offset yield strength on strain rate $\left(10^{-3}\right.$ and $\left.10^{-1} \mathrm{~s}^{-1}\right)$. (Reprinted from Ref. 5, with permission from Elsevier and from Ref. 6 , with permission from Elsevier. HE-4, the alloy $\mathrm{CrFeCoNi} \mathrm{shown} \mathrm{in} \mathrm{(b),} \mathrm{shows} \mathrm{the} \mathrm{exact} \mathrm{same} \mathrm{trend} \mathrm{as} \mathrm{HE-1.} \mathrm{Its} \mathrm{data} \mathrm{points,} \mathrm{despite} \mathrm{not} \mathrm{being} \mathrm{discussed} \mathrm{in} \mathrm{this}$ review, have intentionally not been removed from the original figure.). 
but, because of the small specimen size, tensile strains could not be accurately quantified by making measurements directly on the gage length. ${ }^{17}$ The hardness increase described earlier, and attributed to the precipitation of $\mathrm{NiMn}, \mathrm{Cr}$ and FeCo, causes significant embrittlement of the HEA, with premature fractures occurring at relatively low stresses in the elastic range after a $15 \mathrm{~h}$ anneal at $450^{\circ} \mathrm{C}$. Annealing of the precipitate-containing specimens at higher and higher temperatures above $600^{\circ} \mathrm{C}$ causes them to progressively dissolve, which in turn results in a decrease in strength and a corresponding increase in ductility. ${ }^{17}$ Eventually, after a $1 \mathrm{~h}$ anneal at $800^{\circ} \mathrm{C}$, the HEA is again a singlephase solid solution, and its mechanical properties resemble those of the single-phase HEA produced by a completely different route, namely, recrystallization after cold rolling. ${ }^{6}$

Steady-state flow studies at elevated temperatures reveal two strain-rate-dependent regions of the stress exponent (i.e. the reciprocal of strain-rate sensitivity) in the range $1023-1123 \mathrm{~K}^{25}$ At strain rates above $2 \times 10^{-5} \mathrm{~s}^{-1}$ the stress exponent was determined to be about 5 and the activation energy for deformation about $330 \mathrm{~kJ} / \mathrm{mol}$, suggesting dislocation climb as the main deformation mechanism and $\mathrm{Ni}$, as the slowest diffusing species, the rate-controlling element. At strain rates below $2 \times 10^{-5} \mathrm{~s}^{-1}$ the stress exponent is less than 3 and the activation energy about $280 \mathrm{~kJ} / \mathrm{mol}$. At such strain rates, the dominant deformation process was suggested to be the drag of gliding dislocations (with the diffusion of one of the constituent elements that acts as the solute atom) as the rate-limiting mechanism. Additionally, precipitates formed in the temperature range 1023$1123 \mathrm{~K}$, particularly in samples that were deformed at higher temperatures and lower strain rates (i.e., longer thermal exposure time). The formation of these precipitates causes the redistribution of constituent elements and local depletion of $\mathrm{Mn}$ and $\mathrm{Cr}$, which has the potential to weaken the mechanical strength of the alloy at elevated temperatures. ${ }^{25}$ There are no reports of similar precipitates forming after low-temperature tests.

(a)
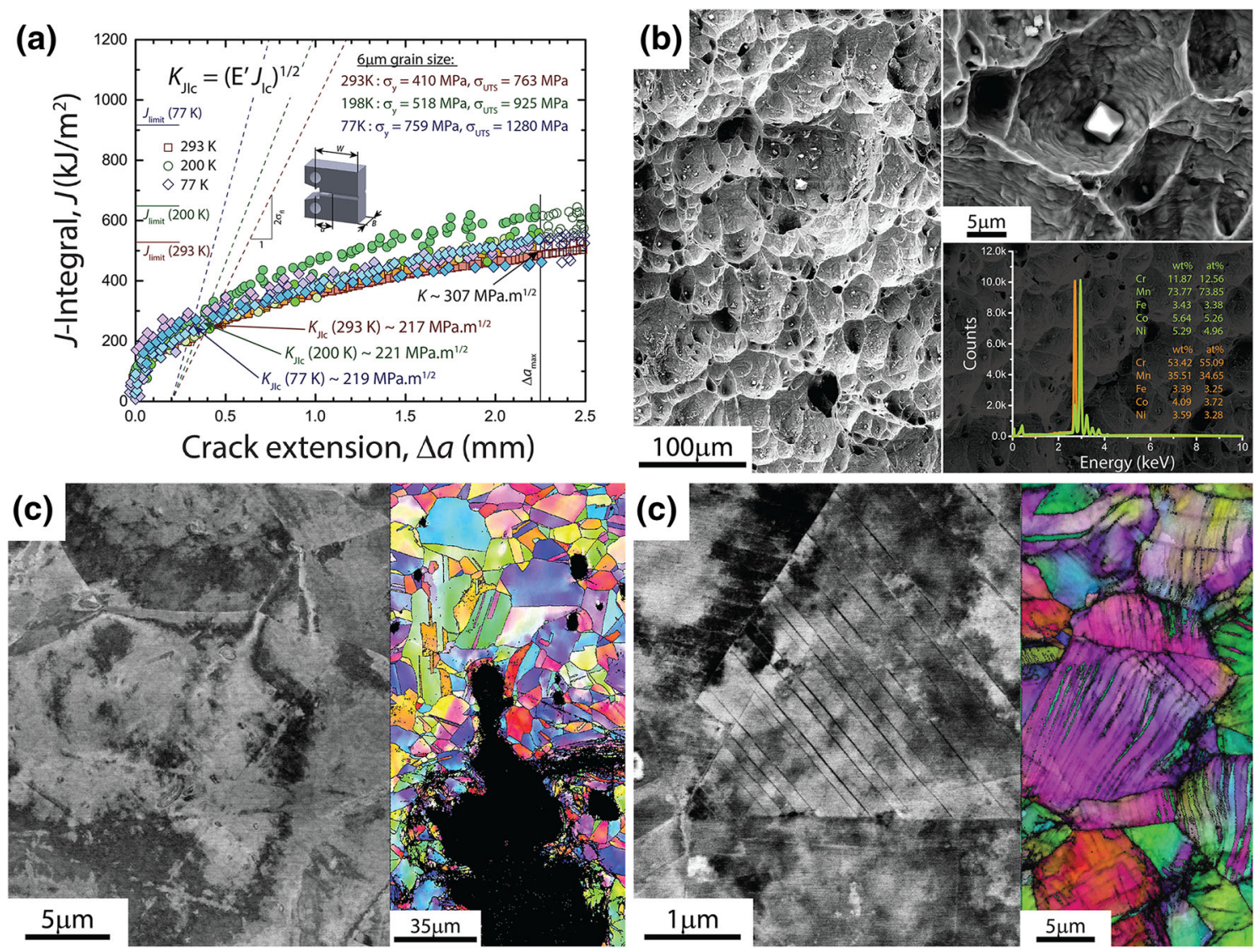

Fig. 7. Fracture toughness, failure mechanism and deformation modes. (a) J-based crack-resistance curves show an increasing crack propagation resistance with crack extension, crack-initiation toughnesses for all tested temperatures $(293 \mathrm{~K}, 198 \mathrm{~K}, 77 \mathrm{~K})$ in excess of $200 \mathrm{MPa} \mathrm{m}^{1 / 2}$ and crack-growth toughnesses above $300 \mathrm{MPa} \mathrm{m}^{1 / 2}$. (b) Failure can be associated with $100 \%$ ductile fracture by microvoid formation from Cr- or Mn-rich particles and their coalescence. (c) Room temperature deformation is mainly carried by dislocation activity obvious through grain misorientations and cell structure formation. (d) At $77 \mathrm{~K}$, deformation-induced nanotwinning as an additional deformation mechanism is obvious in both back-scattered electron microscopy images as well as in electron back-scattered diffraction maps. (Reprinted with permission from the American Association for the Advancement of Science). ${ }^{7}$ 


\section{Fracture Behavior}

Fracture toughness tests performed at $293 \mathrm{~K}$, $198 \mathrm{~K}$ and $77 \mathrm{~K}$ on recrystallized, pre-cracked and side-grooved compact-tension, $\mathrm{C}(\mathrm{T})$ samples of the CrMnFeCoNi alloy with equiaxed grains of $\sim 6 \mu \mathrm{m}$ size show a crack-initiation toughness, $K_{\text {JIc }}$, in excess of $200 \mathrm{MPa} \mathrm{m}{ }^{1 / 2}\left(J_{\mathrm{Ic}} \approx 250 \mathrm{~kJ} \mathrm{~m}^{-2}\right)^{*}$ over the entire temperature range (Fig. 7a). The crackgrowth toughness at crack extensions of $\sim 2 \mathrm{~mm}$ (the maximum extent of cracking permitted by ASTM standards ${ }^{26}$ for this geometry and sample size) increases in a rising crack-resistance curve ( $R$-curve) behavior to $K$ values above $300 \mathrm{MPa} \mathrm{m}^{1 / 2}$ $\left(J \approx 500 \mathrm{~kJ} \mathrm{~m}^{-2}\right)$ at all temperatures. The failure mechanism of the material is $100 \%$ ductile fracture occurring through the formation and coalescence of microvoids (Fig. 7b), the initiation sites are $\mathrm{Cr}$ - or Mn-rich particles that were, similar to the tensile tests, ${ }^{5,6}$ found inside the voids (inset of Fig. 7b). These particles (likely oxide inclusions) seem to have no deleterious influence on mechanical properties at lower temperatures since the alloy without $\mathrm{Mn}$, CrFeCoNi, which has significantly fewer inclusions, behaves very similarly. ${ }^{5}$

Akin to the tensile tests, BSE microscopy and EBSD reveal slip dislocation activity in the form of grain misorientations as the only deformation mechanism at room temperature (Fig. 7c). In contrast, substantial deformation-induced nanoscale twinning occurs at $77 \mathrm{~K}$ (Fig. 7d) together with dislocation slip leading to highly distorted grains and pronounced cell structures. Such extensive plasticity at room temperature results in high strain-hardening exponents of $n \sim 0.4$ which are sustained at low temperatures through extensive nanotwinning leading to the exceptionally high fracture toughness of this alloy between ambient and liquid-nitrogen temperatures.

\footnotetext{
*The extensive plasticity and resulting ductility prior to outright fracture necessitates the application of non-linear elastic fracture mechanics to evaluate the fracture toughness of these alloys; such methodologies have the added advantage of including the plasticity contributions to the toughness and for accounting for stable crack growth. Specifically, $J$-based crack-resistance curves ( $R$-curves), i.e., $J_{\mathrm{R}}$ as a function of crack extension $\Delta a$, were measured for the initiation and growth of cracks. $J$ is the nonlinear strain-energy release rate, i.e., the rate of change in potential energy for a unit increase in crack area in a nonlinear elastic solid. It is the nonlinear-elastic equivalent of the strainenergy release rate $G$. It characterizes the stress and displacement fields at a crack tip in such a solid, and as such can be used to define the onset of fracture there. Provided specific validity criteria for $J$-dominant conditions were met- $J$-dominance requires $b, B \gg 10\left(J / \sigma_{\text {flow }}\right)$, where $b$ is the uncracked ligament width (sample width, $W-a$ ), $B$ the sample thickness and $\sigma_{\text {flow }}$ the flow stress $\left(\sigma_{\text {flow }}=1 / 2\left(\sigma_{\mathrm{y}}+\sigma_{\text {UTS }}\right)\right)$-values of $J$ were back-calculated to determine stress-intensity based toughness values assuming mode $I$ equivalence between $K$ and $J$ through $J=K^{2}$ / $E^{\prime}$, where $E^{\prime}=E$ (Young's modulus) in plane stress and $E /$ $\left(1-v^{2}\right)$ in plane strain ( $v$ is the Poisson's ratio).
}

\section{CONCLUSION}

The $\mathrm{CrMnFeCoNi}$ alloy is an equiatomic singlephase solid solution alloy with a face-centered cubic (fcc) crystal structure that is one of the most promising high-entropy alloys to date, at least in terms of its mechanical properties at room temperature and below. The material has an excellent malleability and recrystallization behavior, which has led to numerous castings that have been wrought into sheets and rods for structural and mechanical analysis of both deformed and fully recrystallized, largely texture-free microstructures with equiaxed grains. Elastic moduli in terms of the shear modulus, $G$, and the Young's modulus, $E$, have been measured between $55 \mathrm{~K}$ and $1000 \mathrm{~K}$ and found to be above 80 $\mathrm{GPa}$ and $200 \mathrm{GPa}$, respectively, at room temperature and below. Tensile tests at low homologous temperatures show that, unlike pure fcc metals, the alloy has a strongly temperature-dependent yield strength but only a very limited strain-rate dependence. Strain rate jump tests above $1000 \mathrm{~K}$ identified two mechanisms of dislocation motion to control the steadystate flow of the material, whereas at room and subzero temperatures the alloy displays an excellent combination of strength, ductility and fracture toughness through a combination of planar-dislocation glide at lower strains and deformation-induced nanoscale twinning at higher strains and lower temperatures. This leads to high strain-hardening exponents resulting in excellent mechanical properties at room temperature and below which gives this high-entropy alloy excellent damage tolerance and makes it a promising candidate material for many structural applications.

Possible future works to extend our understanding of this material but also HEAs in general include study of the mechanical properties in the cast (as opposed to wrought) state and careful characterization of phase stability and its influence on mechanical properties. Furthermore, a detailed analysis of the contribution of the individual elements to the alloy's performance as well as detailed high-resolution studies of dislocation structure would be beneficial in understanding basic deformation mechanisms of this class of materials.

\section{ACKNOWLEDGEMENTS}

This research was sponsored by the U.S. Department of Energy, Office of Science, Office of Basic Energy Sciences, Materials Sciences and Engineering Division.

\section{REFERENCES}

1. B. Cantor, I.T.H. Chang, P. Knight, and A.J.B. Vincent, Mater. Sci. Eng. A 375-377, 213 (2004).

2. J.-W. Yeh, S.-K. Chen, S.-J. Lin, J.-Y. Gan, T.-S. Chin, T.-T. Shun, C.-H. Tsau, and S.-Y. Chang, Adv. Eng. Mater. 6, 299 (2004).

3. C.-Y. Hsu, J.-W. Yeh, S.-K. Chen, and T.-T. Shun, Metall. Mater. Trans. A 35, 1465-1469 (2004).

4. F. Otto, Y. Yang, H. Bei, and E.P. George, Acta Mater. 61, 2628 (2013). 
5. A. Gali and E.P. George, Intermetallics 39, 74 (2013).

6. F. Otto, A. Dlouhý, C. Somsen, H. Bei, G. Eggeler, and E.P. George, Acta Mater. 61, 5743 (2013).

7. B. Gludovatz, A. Hohenwarter, D. Catoor, E.H. Chang, E.P. George, and R.O. Ritchie, Science 345, 1153 (2014).

8. M.J. Yao, K.G. Pradeep, C.C. Tasan, and D. Raabe, Scr. Mater. 72-73, 5 (2014).

9. D. Ma, M. Yao, K.G. Pradeep, C.C. Tasan, H. Springer, and D. Raabe, Acta Mater. 98, 288 (2015).

10. Y. Deng, C.C. Tasan, K.G. Pradeep, H. Springer, A. Kostka, and D. Raabe, Acta Mater. 94, 124 (2015).

11. M. Laurent-Brocq, A. Akhatova, L. Perrière, S. Chebini, X. Sauvage, E. Leroy, and Y. Champion, Acta Mater. 88, 355 (2015).

12. G. Laplanche, O. Horst, F. Otto, G. Eggeler, and E.P. George, J. Alloys Compd. 647, 548 (2015).

13. K.-Y. Tsai, M.-H. Tsai, and J.-W. Yeh, Acta Mater. 61, 4887 (2013).

14. N. Stepanov, M. Tikhonovsky, N. Yurchenko, D. Zyabkin, M. Klimova, S. Zherebtsov, A. Efimov, and G. Salishchev, Intermetallics 59, 8 (2015).

15. G. Laplanche, P. Gadaud, O. Horst, F. Otto, G. Eggeler, and E.P. George, J. Alloys Compd. 623, 348 (2015).
16. A.J. Zaddach, C. Niu, C.C. Koch, and D.L. Irving, JOM 65, 1780 (2013).

17. B. Schuh, F. Mendez-Martin, B. Völker, E.P. George, H. Clemens, R. Pippan, and A. Hohenwarter, Acta Mater. 96, 258 (2015).

18. F. Otto, N.L. Hanold, and E.P. George, Intermetallics 54, 39 (2014).

19. W.H. Liu, Y. Wu, J.Y. He, T.G. Nieh, and Z.P. Lu, Scr. Mater. 68, 526 (2013).

20. F. Zhang, C. Zhang, S.L. Chen, J. Zhu, W.S. Cao, and U.R. Kattner, Calphad 45, 1 (2014).

21. A. Haglund, M. Koehler, D. Catoor, E.P. George, and V. Keppens, Intermetallics 58, 62 (2015).

22. Z. Wu, H. Bei, G.M. Pharr, and E.P. George, Acta Mater. 81, 428 (2014).

23. Y. Wu, W.H. Liu, X.L. Wang, D. Ma, A.D. Stoica, T.G. Nieh, Z.B. He, and Z.P. Lu, Appl. Phys. Lett. 104, 051910 (2014).

24. R.O. Ritchie, Nat. Mater. 10, 817 (2011).

25. J.Y. He, C. Zhu, D.Q. Zhou, W.H. Liu, T.G. Nieh, and Z.P. $\mathrm{Lu}$, Intermetallics 55, 9-14 (2014).

26. E08 Committee, E1820-13 Standard Test Method for Measurement of Fracture Toughness (PA: ASTM International, 2013). 